Bayero Journal of Pure and Applied Sciences, 10(1): 211 - 214

ISSN 2006 - 6996

\title{
DETERMINATION OF PERCENTAGE OF CAFFEINE CONTENT IN SOME ANALGESIC TABLETS
}

\author{
Mahmoud, A.B. \\ Department of Chemistry, Nigeria Police Academy, Wudil-Kano, Nigeria. \\ aminabmahmoud@yahoo.com +2348038475836
}

ABSTRACT

Two methods were employed for the determination of percentage Caffeine content in three brands of analgesic tablets which are; Extraction using only water as a solvent and Extraction using both water and chloroform as solvents, watch glass has been used as the weighing apparatus and the percentage of Caffeine content in each tablets were calculated. . The percentage of caffeine using only water as a solvent in three different tablets; Ibuprofen, Boska, and Panadol Extra were 7.40\%, 5.60\% and 4.60\% respectively. While the percentage of caffeine using both water and chloroform in three tablets were $7.40 \%, 5.50 \%$ and $5.22 \%$. The percentage yields of the analgesic tablets content gave more extract when water and chloroform extraction solvents were used with $98.67 \%, 96.50 \%, 98.31 \%$ for the three tablets respectively.

Keywords: Ibuprofen, Boska, Panadol Extra, Caffeine

\section{INTRODUCTION}

Caffeine (1,3,5 - trimethyl xanthine) and two of its minor isomeric dimethyl xanthines, theobromine and theophyline belong to a group of methylxanthines (Fig.1). It is a purine alkaloid, which is one of the most consumed stimulant. It's natural sources are coffee tree (Coffea Arabica), green tea (Camella sinensis), cola (acuminata), guarana (Paulina cupana), cocoa and yerba mate '(Ilex paraguariensis) (Dobrina et al., 2015). The amount of caffeine found in these products varies; the highest amounts are found in guarana (4-7\%), followed by tea leaves (3.5\%), mate'(0.89-1.73\%), coffee leaves (1.1-2.2\%). Caffeine possess different physiological effects; stimulates central nervous system (CSN). It's action enhances the

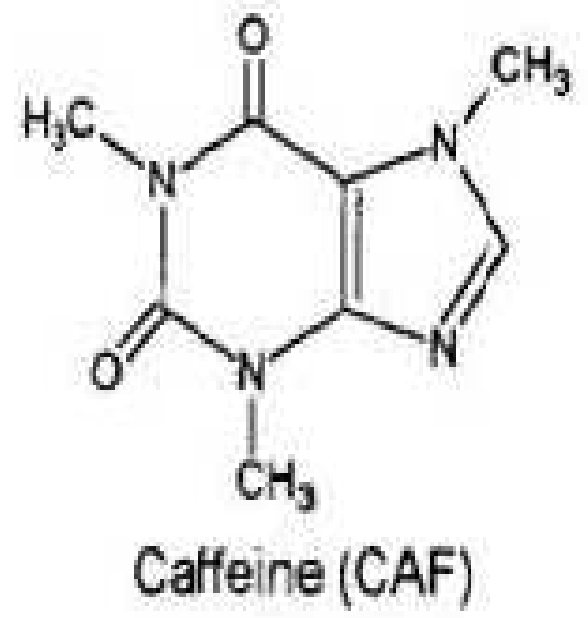

mental activity and physical performance, improves the cognition (Clifford et al., 1990; Dobrina et al., 2015). Caffeine is used in the treatment of mild respiratory depression caused by narcotics and for the treatment of headache and with ergotamine in antimigraine preparations in order to produce a sense of alertness (Bhawani et al; 2015). The objective of the study was to determine the degree of effectiveness between the methods of extraction of Caffeine using water only and using water and chloroform extraction solvents, as a reliable, simpler, and easier methods for the determination of caffeine in order to find caffeine amount consumed. Also to isolate and ascertain that caffeine content varies in the various caffeine - contained tablets.

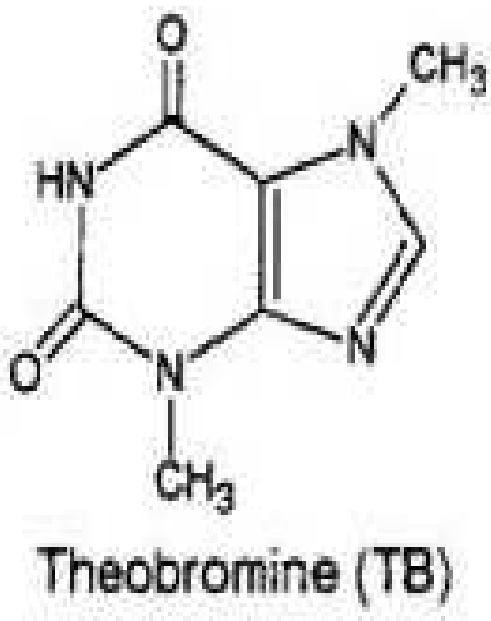

(Figure1) : STRUCTURE OF CAFFEINE AND IT'S ISOMER 
MATERIALS AND METHODS

Sampling of the drugs

Sample of three brands of analgesic tablets; Ibuprofen $(400 \mathrm{mg})$, Boska $(530 \mathrm{mg})$ and Panadol extra (565mg), were purchased from a recognized pharmaceutical chemist in Kano metropolis, Nigeria.

Sample preparation

Two tablets of each drug (weight) were separately placed in a beaker $(500 \mathrm{ml})$ and distilled water $(250 \mathrm{ml})$ was added to dissolved it. The solution was boiled for 25 mins with occasionally stirring. Few drops of honey were added into the warm aqueous solution of caffeine to precipitated the water soluble substances to insoluble salts. The solution was then filtered to remove any solid particles (www.upb.pitt.edu/uploadedfiles/about).

\section{Caffeine Extraction procedure}

Two different solvent extraction methods were employed, which are; extraction by using only water as a solvent and extraction using both water and chloroform. In the first method the filtered caffeine solution was evaporated to about $15 \mathrm{ml}$ on a cleaned watch glass having a recorded weight of $\mathbf{W} 1$.The process was repeated until all the $15 \mathrm{ml}$ of concentrated caffeine solvent was evaporated. The watch glass was removed from the hot plate and was cooled, wiped the moisture at it's bottom , reweighed and recorded as $\mathbf{W} 2$. The difference between; $\mathbf{W}$ and $\mathbf{W} 1$ gave the amount of caffeine extracted; DW. The second method involved the use of water and chloroform extraction solvent. The filtered solution was transferred into distillation bottle and $50 \mathrm{ml}$ of chloroform was added, the solution was shaken and distilled to obtained chloroform at a boiling point of $62^{\circ} \mathrm{C}$. The distilled chloroform solution was transferred into the beaker and heated over the boiling water bath. The solution was evaporated to about $15 \mathrm{ml}$ and removed from heat. The resultant solution was poured into weighed watch glass; $\mathrm{W} 1$, and placed over boiling water bath and evaporated repeatedly, until all the concentrated caffeine was evaporated. The watch glass was removed, allowed to cool and re-weighed as W2 (www.upb.pitt.edu/uploadedfiles/about).

Quantitative caffeine determination

Quantitative analysis of caffeine in the samples was performed by calculating the following:

The weight of caffeine extracted (DW), the percentage yield, $\mathrm{C} \% / \mathrm{T} \%$ the theoretical percentage of caffeine (T\%), and experimental percentage or percentage of caffeine extracted (C\%); using the equations (1) and (2)

DW $=$ W2 -W1-----(1)
Percentage yield $=\mathrm{C} \% / \mathrm{T} \% \times 100-----(2)$

Where:

T\% =Weights of two Caffeine tablets used / Weight of Caffeine tablets used $\times 100$

$\mathrm{C} \%=$ Weight of Caffeine extracted / Weight of two Caffeine tablets used $\times 100$

\section{RESULTS AND DISCUSSION}

Three different drugs containing caffeine were analyzed for the percentage of the caffeine content in each using solvents extraction methods. The first method was carried out with only water as the solvent which gave the extracted caffeine content (DW) for the three tablets; $0.0590 \mathrm{~g}$ for Ibuprofen, $0.0594 \mathrm{~g}$ for Boska and $0.0520 \mathrm{~g}$ for Panadol Extra. This is similar to that obtained in the study conducted by Letic et al.,(2016), in which the caffeine content in food; ranged from $0.005 \mathrm{~g}-0.158 \mathrm{~g}$, and $0.064 \mathrm{~g}$ in Panadol Extra. The extracted caffeine content using water and chloroform extraction solvents for the tablets were; $0.0590 \mathrm{~g}$ Ibuprofen, $0.0580 \mathrm{~g}$ Boska, $0.0590 \mathrm{~g}$ Panadol Extra, is also similar to the caffeine content found in the study of Letic et al.,(2016). The percentage of caffeine determined in the three tablets using water as the extraction solvent were $7.40 \%$ for Ibuprofen, $5.60 \%$ for Boska, and $4.60 \%$ for Panadol Extra (Fig.2).This slightly correlates well with that reported by Clifford et al.,1990;Dobrina et al.,2015), highest percentage of caffeine of $4-7 \%$ in guarana natural plant . While the percentage of Caffeine extracted using Water and Chloroform solvent, were $7.40 \%$ for Ibuprofen, $5.50 \%$ for Boska, and 5.22\% for Panadol extra (Fig. 3). These percentages were also in agreement with the findings of Clifford et al.,1990 and Dobrina et al., 2015. The percentage yield of both tablets from water solvent; gave more extract of Ibuprofen (98.67\%) and Boska $(98.25 \%)$,but less caffeine percentage yield with respect to Panadol extra (86.63\%). But in comparison to that obtained using water and chloroform solvent, all the three tablets content of caffeine yield more extract; $98.67 \%$, $96.49 \%$ and $98.31 \%$ respectively (Figure 4 ). These percentage yields in both water and water/ chloroform were higher than that obtained by Jones (2015); which was $32.73 \%$ of the caffeine content in lipton tea black.

Figure 2:Extraction of Caffeine content from three analgesic tablets using water only

Key: $\mathrm{Wd}=$ exact weight of caffeine tablets, $\mathrm{Dw}=$ extracted weight of caffeine

$\mathrm{T} \%=$ theoritical percentage of Caffeine in the three tablets, $\mathrm{C} \%=$ experimental Caffeine percentage in the three tablets. 


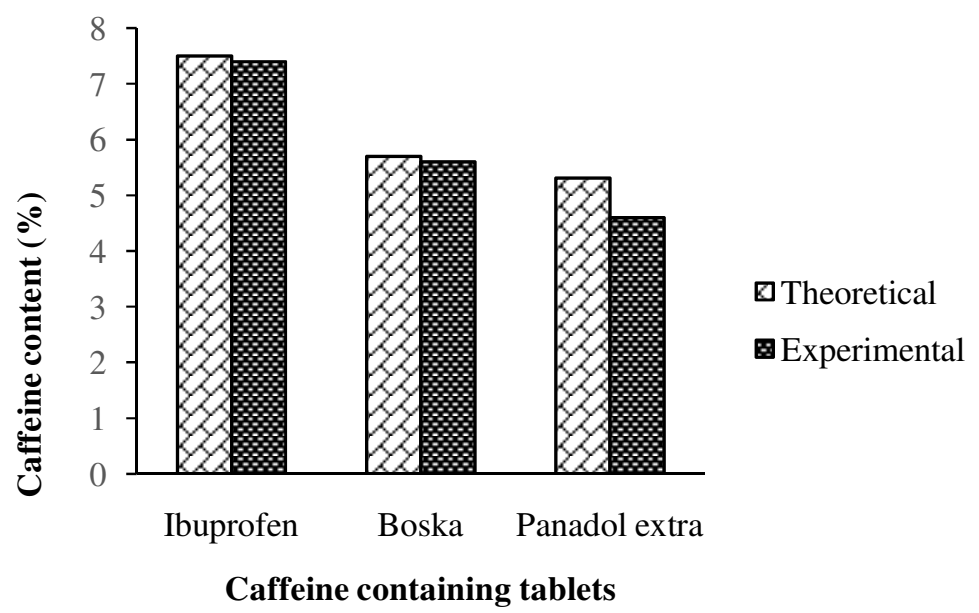

Figure 2: Extraction of Caffeine content from three analgesic tablets using water solvent

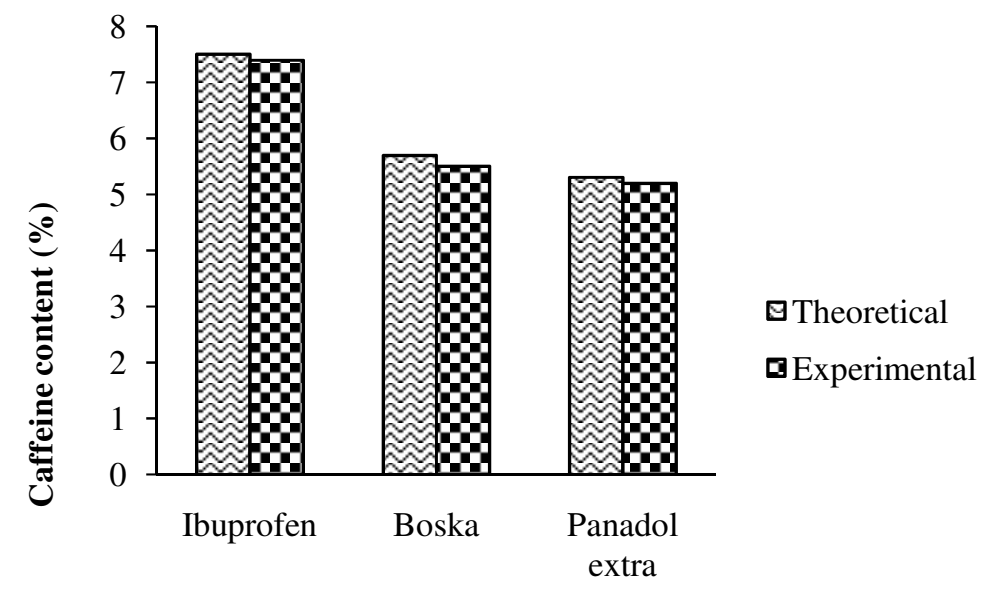

Caffeine containing tablets

Fig. 3:Extraction of Caffeine using Water and chloroform solvent

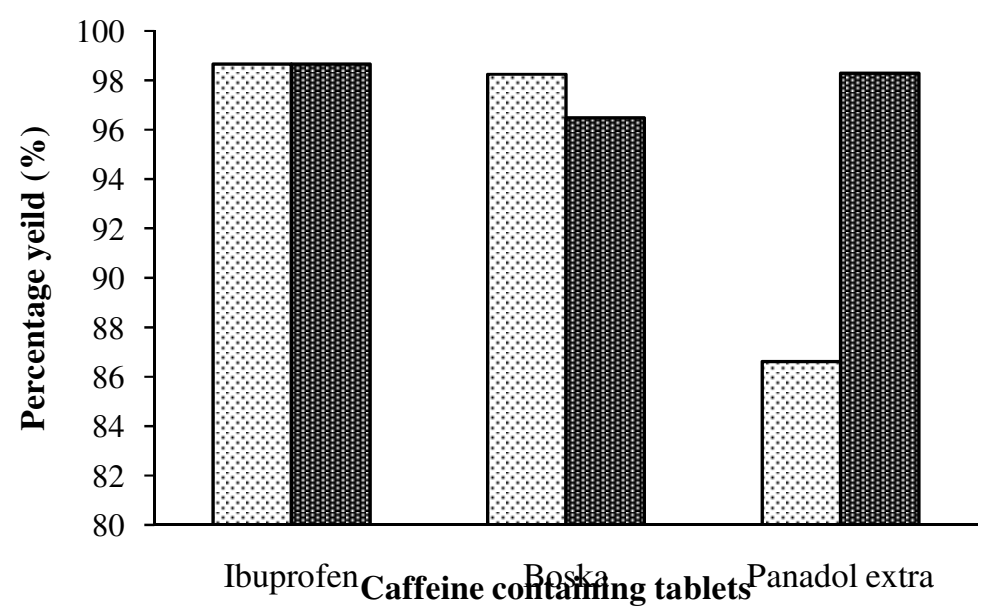

Water only

国 Water and..

Fig. 4.Percentage yield for the Caffeine content 


\section{CONCLUSION}

The percentage of caffeine using only water as the extraction solvent in the three different tablets; ibuprofen, boska, and Panadol extra were $7.40 \%, 5.60 \%$ and $4.60 \%$ respectively. While the percentage of caffeine using both water and chloroform in three tablets were $7.40 \%, 5.50 \%$ and $5.22 \%$. Therefore, based on the results obtained from the analysis of the above three tablets using both water and chloroform as solvent gave high Caffeine extract percentage than using only water as the extraction solvent. In comparing the percentage yield (Fig. 3), and the extent of effectiveness, the method of extraction using only water as solvent yield more extract of Boska caffeine content than using both water and chloroform as solvent. But in case of Panadol Extra percentage yield using water and chloroform solvent gave more extract.

\section{REFERENCES}

Bhawani SA, Fong SS, Ibrahim MMN;(2015).S spectrophotometric Analysis of Caffeine. International Journal of Analytical Chemistry. 2015(2015) http://dx.doi.org/10.1155/2015/17023 9

Clifford M N, and Ramirez-Martinez JR,(1990). Chlorogenic acids and purine alkaloids contents of mate(Ilex paraguarensis) leaf and beverage, Food Chemistry, 35:13-21

Dobrina S, Soceanu A, Popescu V,Stanciu G, and Smallberger S, (2012). Optimization of a UV/VIS Spectrophotometric method for caffeine analysis in tea, coffee, and other beverages, Journal of Chemistry and Chemical Engineering, Biotechnology, Food Industry.14(2):071078.

\section{Recommendation}

I recommend the study on another tablets that contain caffeine. since this study was conducted on specific aforementioned tablets (ibuprofen, boska and panadol extra). As water and chloroform were used for these extraction. I recommend the use of other solvents like Methanol or Ethanol.

\section{Acknowledgement}

I acknowledged the assistance and support given to me by my institution/employer; Nigeria police Academy, Wudil, Kano-Nigeria. Endlessly my special acknowledgement goes to my humble mentor, Prof. Musa Ibrahim for his corrections and criticisms. I also thank Nazifi Balarabe; my Ph.D colleague at A.B.U zaria and a staff at B.U.K, Kano.

Letic NG, Rakie B, Sefer E, Milanovic, M, Niksic M, and Milie N, (2016).Quantitative determination of caffeine in different matrices. Macedonian pharmaceutical bulletin, 62(1):77-84

Purcarea C, Chis A, Vicas S, and Fodor A,(2008).Comparative studies about caffeine content in Roasted Ground Coffee and in China black Tea. Fascicula: ecolotoxicologie, zootecnie SI Technology 11 De Industrie Alimentara,7(7):966-971

John D., (2015). The extraction of caffeine from concentrated Lipton Black Tea. Orgo-caffeine-Lab-Report-1.docx

www.upb.pitt.edu/uploadedfiles/about 